\title{
Informatics in the Times of Change
}

\author{
Sabine Koch, President of IMIA \\ Karolinska Institutet, Stockholm, Sweden
}

To me, biomedical and health informatics (BMHI) has always been an exciting field to work in, where I met excellent colleagues who are driven by the desire to improve health for all. BMHI is evolving rapidly, and new technological developments provide us with improved tools for better clinical problem solving and elicitation of new knowledge. New challenges arise all the time, whereof some challenges are solved by informatics, and some challenges (aka interoperability) seem to stay forever. Around the world, healthcare and health policy decision makers' consciousness about informatics as a key enabler for the future of healthcare and healthcare research increases steadily. Nevertheless, I never experienced such an enormous pull for informatics solutions in the healthcare field as it has been this year, since the coronavirus disease 2019 (COVID-19) pandemic.

Suddenly, digitalization is key. In response to the COVID-19 pandemic, the use of telehealth solutions accelerates around the world, primary care and hospitals switch to digital forms of patient encounters whenever possible, and many countries provide self-tracking apps for their citizens. Around the world, countries are confronted with the need for high-quality data and methods to link, integrate, and analyze them for informed decision and policy making. The discussions around the world regarding the ethical handling of this crisis and, not least, the information produced and shared show the timely relevance of this International Medical Informatics Association (IMIA) Yearbook.

In IMIA, several initiatives related to the COVID-19 pandemic took place during the last months:

On March 27, 2020 IMIA's Academy submitted a formal statement to the World Health Organization (WHO) in response to the current COVID-19 global pandemic [1]. The statement emphasizes the use of health informatics methodology and information and communication technology (ICT) in combating the current COVID-19 pandemic and future outbreaks. It further stresses the essential role of biomedical and health informatics in pandemic surveillance, notification and continued delivery of evidence-based best practices, and urges for the accelerated use of these methodologies and technologies as a critical success factor for enhancing the health and wellbeing of individuals and the sustainability of health care systems worldwide.

The Special Interest Groups (SIGs) for Nursing Informatics (NI) in IMIA and the European Federation of Medical Informatics (EFMI) (IMIA NI SIG and EFMI NI SIG) have collaborated to offer online resources to support nurses in response to the COVID-19 pandemic [2]. Members of the IMIA Special Interest Group for Students and Emerging Professionals (IMIA SEP SIG) collaboratively created a survey aimed at understanding the integration of health information technology in response to the COVID-19 pandemic [3]. The aim was to openly share the expertise, lessons learned, and challenges of health informaticians during this time and thereby help the broader health informatics community who are likely facing similar challenges during this pandemic.

Highly relevant in the context of COVID-19 is also the book "Fundamentals of Telemedicine and Telehealth" [4], recently published by the IMIA Telemedicine Working Group. The publication provides an overview on the use of ICTs to solve health problems, especially for people living in remote and underserviced areas.

Several other IMIA initiatives, in relation to the goals of the IMIA 2017 Strategic Plan [5], are ongoing under the leadership of the different IMIA Vice Presidents and IMIA Liaison Officers [6]. Examples include the revision of the IMIA Recommendations on Education and its relation to the IMIA
Accreditation Program, collaboration activities with the World Health Organization, collaboration between the IMIA Working Groups and Special Interest Groups, the development of new membership models, and the planning of MEDINFO 2021.

I am grateful for such a great team of very engaged colleagues, that I have the pleasure to work with, and I would like to take the opportunity to cordially thank Brigitte Séroussi, who guided the work with the IMIA Yearbook as VP Services since 2016, as she will leave this position in November 2020. The Yearbook, that you read on your screens, could not have been timelier in these times of change where the use of informatics increases and ethical norms to secure the privacy rights of the individual play an ever more important role.

\section{References}

1. Statement from the International Academy for Health Sciences Informatics (IAHSI), the Academy of the International Medical Informatics Association (IMIA) to the Director General of the WHO on the Use of Informatics in Pandemic Situations. Available from: https://imiamedinfo.org/wp/statement-from-the-internationalacademy-for-health-sciences-informatics-iahsithe-academy-of-the-international-medicalinformatics-association-imia-to-the-directorgeneral-of-the-who-on-the-use/ [last accessed on July $\left.1^{\text {st }}, 2020\right]$

2. IMIA Nursing Informatics Special Interest Group https://imia-medinfo.org/wp/sig-ni-nursinginformatics/ [last accessed on July $1^{\text {st }}, 2020$ ]

3. Online survey http://covidhitimpact.com/ [last accessed on July $\left.1^{\text {st }}, 2020\right]$

4. Gogia S, editor. Fundamentals of Telemedicine and Telehealth. Academic Press; 2019. Available from: https://www.elsevier.com/books/fundamentalsof-telemedicine-and-telehealth/gogia/978-0-12814309-4 [last accessed on July 1st, 2020]

5. IMIA Strategic Plan - Executive Summary, 2017 https://imia-medinfo.org/wp/imia-strategic-plan/ [last accessed on July $1^{\text {st }}, 2020$ ]

6. Current IMIA Board https://imia-medinfo.org/wp/ imia-board/ [last accessed on July $1^{\text {st }}, 2020$ ] 